\title{
OCORRÊNCIA DA PODRIDÃO ESTILAR EM TOMATEIROS (Lycopersicon esculentum Mill.) SOB O EFEITO DE REGULADORES DE CRESCIMENTO*
}

\author{
Paulo R. C. Castro ** \\ EURÍPEDES MALAVOLTa ***
}

\author{
RIESUMO
}

Estudaram-se em condições de casa de vegetação os efeitos da aplicação de reguladores de crescimento na ocorrência da podridão, estilar nos frutos de tomateiro cultivar "Miguel Pereira". Observou-se que ácido giberélico na concentração de $100 \mathrm{ppm}$ promoveu alta incidência da anomalia fisiológica em plantas tratadas com altas dosagens de sulfato de amônio. Sob as mesmas condições, tomateiros pulverizados com ácido succínico -2.2-dim tilhidrazida $4.000 \mathrm{ppm}$, cloreto de (2-cloroetil) trimetilamônio $2.000 \mathrm{ppm} \mathrm{e}$ ácido-3 - indolacético $100 \mathrm{ppm}$, apresentaram baixa incidência de podridão estilar. Efetuaram-se determinações dos teores de $\mathrm{N}$, $\mathrm{P}, \mathrm{K}, \mathrm{Ca}$ e $\mathrm{Mg}$ nas folhas, hastes e frutos dos tomateiros normais e daqueles mostrando a anomalia fisiológica. Realizaram-se análises químicas dos substratos de plantio e foi proposto um mecanismo da incilência da podridão estilar em tomateiros.

\section{INTRODUÇÃO}

A utilização de reguladores de crescimento no tomateiro é uma conseqüência da evolução das técnicas de cultivo; sendo que esses produtos químicos têm sido empregados principalmente para induzir o florescimento, aumentar a fixação dos frutos e promover a maturação. Apesar de se conhecer alguns efeitos dos reguladores de crescimento na morfologia e frutificação do tomateiro, pouco se sabe sobre seus efeitos na ocorrência da podridão estilar e suas prováveis causas fisiológicas.

\footnotetext{
* Trabalho subvencionado pela Fundação de Amparo à Pesquisa do Estado de São Paulo (FAPESP); parte da Tese apresentada pelo primeiro autor para obtenção do título de Doutor pela U.S.P. Entregue para publicação em 17/8/1976.

* Departamento de Botânica. E.S.A. "Luiz de Queiroz" -.. U.S.P.

** Departamento de Química e CENA. E.S.A. "Luiz de Queiroz" - U.S.P.

OBS.: Considerar aspas duplas referentes às cultivares como sendo aspas simples.
} 
BRYAN \& READ (1972) verificaram a ocorrência de parede cinzenta em 17 e $22 \%$ dos frutos de tomateiros pulverizados no estágio de plântula com ácido (2-cloroetil) fosfônico (CEPA) e ácido succínico-2,2-dimetilhidrazida $(\mathrm{SADH})$, respectivamente, comparativamente com $36 \%$ da anomalia em plantas pulverizadas com água. Plantas tratadas com cloreto de (2-cloroetil) trimetilamônio (CCC) apresentaram $44 \%$ dos frutos com parede cinzenta. Quando SADH e CCC foram aplicados em seqüência, o CCC mascarou os efeitos benéficos do SADH em reduzir a ocorrência da anomalia, entretanto, não houve aumento na incidência de parede cinzenta quando CCC foi aplicado após a pulverização com CEPA. Aplicações simultâneas de SADH e CEPA não se mostraram aditivas em seus efeitos na redução da ocorrência da anomalia. A produção total das plantas tratadas com SADH mostrou-se 58\% superior ao controle. A produção das plantas tratadas com CEPA concentrou-se na última colheita, entretanto, a produção total mostrou-se semelhante ao controle. HUANG \& HUNG (1957) aplicaram ácido para-clorofenoxiacéico em 3 concentrações, em tomateiro. Não observaram aumento na porcentagem de frutos anormais, porém, verificaram grande aumento no número de lóculos verdes. A auxina no teor de $30 \mathrm{ppm}$ promoveu maior aparecimento da anomalia na primeira colheita. O número de frutos túrgidos não foi aumentado pela aplicação da auxina, sendo que o grau de turgescência foi aumentado proporcionalmente à concentração da solução utilizada. BATAL et alii (1972) verificaram que a pulverização de frutos de tomateiro, com reguladores de crescimento, reduziu significativamente a ocorrência de rachadura dos frutos. A incidência da anomalia na cultivar suscetível tratada com ácido-3-indolacético (IAA), ácido giberélico (GA), ácido naftalenacético (NAA) e cinetina, foi semelhante à incidência na cultivar resistente à rachadura. A morfologia do pericarpo dos frutos, da cultivar suscetível, tratados com os reguladores de crescimento, mostrou-se mais semelhante à cultivar resistente, do que os frutos da cultivar suscetível, não tratados. SINGH \& YOUNG (1971) observaram que o CCC mostrou promover alterações no crescimento e transpiração de plantas de tomateiro e, conseqüentemente, na incidência de rachadura dos frutos. CASTRO (1973) verificou menor incidência da podridão estilar em tomateiros tratados com CCC nas concentrações de 2.000 e 5.000 ppm, em relação às plantas controle e àquelas tratadas com $500 \mathrm{ppm}$ do retardador de crescimento. LORD et alii (1967) verificaram que aplicação de SADH nas concentrações de 1.000 a 5.000 ppm, em macieiras, reduziram a ocorrência de anomalia interna nos frutos.

HOFF et alii (1974) observaram que a forma de nitrogênio aplicada possui efeito pronunciado nos níveis de aminoácidos livres em tomateiro. Quando comparada com a forma nítrica, a forma amonical promove maiores aumentos em aminoácidos livres nas folhas novas, nas folhas maduras e nos frutos. Plantas submetidas às duas formas de nitrogênio mostraram níveis intermediários. A aplicação de cálcio em frutos desenvolvendo-se com nitrogênio amonical, resultou em níveis de aminoácidos nos frutos semelhantes àqueles desenvolvendo-se com a forma nítrica. 
A toxicidade da forma amonical mostrou-se acompanhada por grandes aumentos nos níveis de ácido gama-aminobutírico e serina nas folhas. Isso sugere que a toxicidade do amônio é uma manifestação da deficiência intracelular de cálcio. WILCOX et alii (1973) verificaram que a adubação do tomateiro com nitrogênio amonical geralmente resulta em redução no crescimento, assim como na redução dos teores de cálcio e magnésio nos tecidos até níveis de deficiência ou próximos desses, quando comparado com planta adubada com a forma nítrica. Adubação das plantas com uma mistura de nitrogênio amonical e nítrico, resultou em níveis intermediários de cálcio e magnésio nos tecidos, entre as plantas que receberam nitrogênio amonical e aquelas que receberam a forma nítrica. A forma amonical aplicada durante a frutificação do tomateiro, resultou em um rápido desenvolvimento de podridão estilar nos frutos, provavelmente, devido à influência do nitrogênio amonical na absorção de cálcio. Aumentando em 4 vezes a concentração de potássio, ocorreu redução significativa no teor de cálcio e de magnésio. Considerando o efeito da competição iônica na absorção desses elementos, foi demonstrado que o aumento em 4 vezes do potássio na solução não reduziu o teor de cálcio e magnésio no tecido em nível próximo da redução promovida pelo amônio. O conteúdo de potássio nas folhas do tomateiro não foi afetado pelo amônio. Aumento na concentração de cálcio e magnésio na solução nutritiva com amônio, não afetou o teor de potássio na extremidade da haste do tomateiro. As folhas de tomateiro tratado com nitrogênio amoniacal mostraram-se com teor mais elevado de fósforo do que tratado com nitrato. SHEAR (1975) considerou que adubação nitrogenada durante o período inicial de desenvolvimento dos frutos atua na redução do teor de cálcio nos frutos. O estímulo do nitrogênio para o crescimento, promove uma região de utilização preferencial de cálcio que prejudica sua disponibilidade aos frutos. REDMOND (1975) observou que aplicação de nitrogênio na forma amonical promove uma maior redução no transporte de cálcio do que a utilização de nitrato. ANDERSEN (1971) verificou que aplicação de altas concentrações de fósforo promove diminuição no teor, assim como na absorção, de cálcio. BROOKS (1914) considerou que a aplicação de fertilizantes com altos teores de potássio promove a ocorrência da podridão estilar. MALAVOLTA et alii (1975) estabeleceram equações relacionando a ocorrência da podridão estilar com os níveis de cálcio, potássio e magnésio trocáveis no solo. Verificaram que a ocorrência de podridão estilar, provocada pela aplicação de sulfato de amônio, é reduzida pelo tratamento dos tomateiros com CCC. Observaram ainda que o retardador de crescimento promoveu aumento no potencial osmótico das plantas. Consideraram também importante a competição entre os frutos e as brotações pelo cálcio conduzido pela corrente transpiratória, na ocorrência da podridão estilar. KNAVEL (1969) verificou que plantas de tomateiro tratadas com CCC mostraram-se mais resistentes à seca do que aquelas tratadas com SADH. Tomateiros que sofreram aplicação de CCC ou SADH revelaram-se mais resistentes à seca e verdes mais escuros do que o controle; sendo que as plantas tratadas com SADH 
contém mais clorofila e suas folhas possuem mais células no parênquima paliçádico do que as controle. Tomateiros tratados com CCC contêm $\mathrm{N}, \mathrm{P}, \mathrm{Ca}$ e $\mathrm{Mg}$, mas menos $\mathrm{K}$ do que as plantas controle. Em apenas um dos três experimentos, plantas tratadas com SADH apresentaram menos $\mathrm{Ca}$ do que o controle; mas o retardador de crescimento não afetou o conteúdo de $\mathrm{Mg}$ nas hastes e folhas.

MAYNARD et alii (1957) verificaram em três variedades de tomateiro desenvolvendo-se em areia, que a incidência da podridão estilar diminui significativamente com o aumento nos níveis de cálcio. Não se encontrou diferenças entre as variedades, na severidade da podridão estilar. O teor de cálcio nos frutos normais foi significativamente superior ao encontrado em frutos afetados pela podridão estilar. Aumentou o teor de cálcio nos frutos quando se elevou o nível de cálcio na solução, sendo que as diferenças no conteúdo de cálcio nos frutos das diferentes variedades não se mostraram significativas. O teor de potássio nos frutos não foi afetado pela variedade, pelos níveis de cálcio, ou pela presença da podridão estilar. DECHEN et alii (1973) verificaram o efeito de diferentes níveis de cálcio na solução nutritiva, no desenvolvimento, no número de frutos e no teor de cálcio nas plantas de tomateiro. Observaram sintomas de podridão estilar nas linhagens Kada e Samano com aplicação de níveis inferiores a $200 \mathrm{ppm}$ de cálcio na solução nutritiva. Ambas as linhagens acham-se bem supridas em cálcio, quando a primeira folha apresentar concentração porcentual de cálcio entre 3,11 e 3,25, aos 90 dias de idade da planta. Frutos livres de podridão estilar apresentam a concentração porcentual de cálcio entre $0,16 \mathrm{e}$ 0,21 para a linhagem Samano e de 0,15 e 0,24 para a linhagem Kada. RESNIK (1966) observou que existem fortes interações entre o cálcio e o potássio, tanto na absorção como na translocação, de natureza geralmente antagônica, exceto um certo estímulo na absorção de potássio, pelo cálcio quando a relação cálcio/potássio do meio é baixa. GERALDSON (1957) observou que o excesso de amônio, potássio e magnésio solúveis, ou a deficiência em cálcio solúvel, aumenta a incidência de podridão estilar. RALEIGH \& CHUCKA (1944) consideraram que o equilíbrio entre os elementos nutritivos no substrato é o fator mais importante na incidência da podridão estilar. A anomalia foi induzida por altos teores de nitrogênio, magnésio e potássio, além de ser provocada por baixos níveis de cálcio. A condição de desequilíbrio nutricional pode causar a anomalia por impedir a utilização da quantidade necessária de cálcio para a formação normal do fruto. Quando a concentração de cálcio nos frutos mostra-se inferior a $0,2 \%$, verifica-se a incidência de podridão estilar em alguns frutos.

WIERSUM (1966a) estudou o suprimento de cálcio nos frutos e nos tecidos de reserva, com relação ao movimento hídrico, em tomateiro. Verificou que a incidência da podridão estilar estilar foi aumentada em plantas que tiveram sua transpiração restringida ou cujos frutos sofreram incremento na taxa de crescimento. Crescimento lento foi associado com baixa ocorrência da anomalia. Análises dos frutos confirmaram 
uma alta correlação entre a anomalia e a relação $\mathrm{K} / \mathrm{Ca}$. O conteúdo de cálcio mostrou-se inferior em frutos de plantas submetidas à restrição na transpiração. Um incremento na taxa de crescimento do fruto foi associado com aumento em potássio. Frutos contendo menos que 800 ppm de cálcio na matéria seca, são sempre afetados com a podridão estilar; sendo que aqueles com teores acima de $1.200 \mathrm{ppm}$ são sadios. ROBBINS (1937) considerou que no desenvolvimento de tomateiros em substrato com altas concentrações de nutrientes, o crescimento dos tecidos pode ser limitado por um atraso na disponibilidade hídrica. Observou que um resulado desse atraso na pronta disponibilidade de água nos tecidos vegetais é o desenvolvimento da podridão estilar dos frutos, que ocorre em alta porcentagem quando soluções nutritivas com altas concentrações dos elementos, são empregadas. Qualquer fator que diminua a taxa de absorção de água ou aumente a taxa de transpiração da planta, pode aumentar a probabilidade de incidência da podridão estilar. REDMOND (1975) considerou que o transporte no floema mostra uma resposta menos imediata ao estresse hídrico e aos reguladores de crescimento do que no xilema. Pulverizações com o ácido triiodobenzóico (TIBA) reduzem consideravelmente o transporte de cálcio aplicado nas raízes. Como nos estágios iniciais do desenvolvimento dos frutos, o fluxo hídrico para os mesmos é efetuado predominantemente através do xilema onde o cálcio move-se com facilidade, e nos estágios finais de desenvolvimento predomina o fluxo hídrico pelo floema onde o cálcio move-se lentamente, a localizacão do fluxo pode acelerar o suprimento de cálcio para o fruto. WIERSUM (1966b) considerou que o transporte por fluxo massal do floema fornece a água e a maioria dos nutrientes necessários para os frutos, mas năo fornece teores adequados de cálcio. Observou que o conteúdo de cálcio desses frutos, particularmente nos tecidos de reserva, é extremamente baixo, podendo resultar na ocorrência de anomalias locais. Mostrou que durante o crescimento rápido, muito pouca ou nenhuma água e cálcio podem entrar nos frutos do tomateiro. Frutos confinados em sacos de polietileno apresentaram menor conteúdo de cálcio. KHARANYAN (1967) observou que o conteúdo total de água nas folhas de feijoeiro foi substancialmente reduzido sete a nove dias após uma irrigacão; sendo que as plantas tratadas com CCC mostravam ainda condições hídricas favoráveis. No final do ensaio verificou que as folhas das plantas controle apresentavam-se murchas; sendo que o conteúdo de umidade no solo era inferior com relação ao das plantas tratadas com CCC. No caso do tratamento com CCC, a quantidade de água fracamente ligada nas folhas era sempre a metade com relação ao controle; sendo que a quantidade de água fortemente ligada aumentou, o que promoveu um incremento nas forças de retenção da água e uma economicidade no consumo da umidade. A perda de água por folhas de plantas tratadas com CCC foi apreciavelmente reduzida e a força de retenção hídrica mostrou-se 2 atm mais alta. Observou-se que a produção das plantas tratadas com CCC mostrou-se algo superior com relação ao controle. O CCC aplicado em irrigação exerceu um efeito pronunciado nas condições hídricas do 
feijoeiro. Após cessar a irrigação, plantas tratadas anteriormente com CCC apresentaram alto conteúdo de água nas folhas, o déficit de saturação mostrou-se pequeno e a concentração de fluido celular nas folhas e sua pressão osmótica revelaram-se baixas, enquanto sob as mesmas condiçốes observou-se um substancial déficit hídrico nas plantas controle. Sob a ação do CCC, a capacidade de retenção hídrica das folhas é aumentada, o que é parcialmente explicado por um incremento na quantidade de água ligada. Considerou que isso está associado com uma mudança no estado e na estrutura de proteínas determinantes da hidratação. CASTRO \& BALLESTERO (1977) verificaram redução na transpiração do tomateiro "Miguel Pereira", promovida pela aplicação de SADH e CCC. JOHANSEN (1954) observou que o IAA não afetou o comportamento estomático quando aplicado em folhas de Sinapis alba na dosagem de 0,6 mM. Aplicação do regulador de crescimento na concentração de $3 \mathrm{mM}$, em irrigação de plantas envasadas, induziu o fechamento estomático, mas esse efeito foi aparentemente indireto, uma vez que ocorreu uma reabertura estomática quando as folhas das plantas tratadas foram cortadas e imersas em água ou em solução de IAA 0,6 mM. LIVNE \& VAADIA (1965) verificaram a taxa de transpiração e a abertura estomática em folhas destacadas de cevada com suas bases imersas em soluções de cinetina e água (controle). A cinetina eleva a taxa transpiratória em folhas maduras completamente desenvolvidas mas não afeta folhas novas.. A abertura estomática foi também estimulada pela cinetina. O ácido giberélico também estimulou as taxas de transpiração. . Adenina e IAA não afetaram a transpiração, que foi porém reduzida pela ação da actinomicina-D.

O presente trabalho teve como finalidade estudar os efeitos de reguladores de crescimento na incidência da podridão estilar e estabelecer um mecanismo de suas prováveis causas fisiológicas.

\section{MATERIAIS E MÉTODOS}

O experimento foi realizado em condições de casa de vegetação, sendo que estudou-se a ocorrência de podridão estilar, provocada pela aplicação de sulfato de amônio no solo, em plantas tratadas com reguladores de crescimento.

No experimento, iniciado em 2 de maio de 1975, em Piracicaba (SP), realizou-se a semeadura do tomateiro cultivar "Miguel Pereira" em caixa de madeira com solo esterilizado, no interior de casa de vegetação.

Efetuou-se o transplante em 15/05/75 para vaso de cerâmica com 14 litros de capacidade total contendo 12 litros de solo com 1,9\% de matéria orgânica; $\mathrm{pH} 6,6 ; \mathrm{Al}, \mathrm{Ca}$ e $\mathrm{Mg}$ no teor de, respectivamente, 0,0, 2,5 e 0,8 e.mg/100 ml de T.F.S.A.; finalmente 155 e acima de $1.00 \mu \mathrm{g} / \mathrm{ml}$ de T.F.S.A., de $\mathrm{K}$ e P, respectivamente. No transplante colocaram-se três plântulas por vaso, tendo-se realizado o desbaste de 
duas delas em 05/06/75,, a fim de uniformizar o experimento. Efetuaram-se os demais tratos culturais normais para a cultura do tomateiro.

Além do tratamento controle aplicou-se cloreto de (2-cloroetil) trimetilamônio (CCC) na concentração de $2.000 \mathrm{ppm}$, ácido succínico 2,2-dimetilhidrazida (SADH) na dosagem de $4.000 \mathrm{ppm}$, ácido giberélico (GA) 100 ppm e ácido 3-indolacético (IAA) na concentração de 100 ppm. Utilizaram-se 9 repetições, tendo-se mantido uma planta por vaso por repetição. As aplicações dos reguladores de crescimento foram realizadas em 12/06/75, por pulverização, utilizando-se uma solução aquosa. Nesta ocasião as plântulas apresentavam 4 folhas definitivas.

Aplicou-se sulfato de amônio em cobertura em 27/06/75 e 05/07/75, na dosagem de $1 \mathrm{~g} / 1$ de solo; em 23/07/75 e 31/07/75, na concentração de $2 \mathrm{~g} / 1$ de solo; finalmente em 04/08/75, 11/08/75 e 08/09/75, na dosagem de $4 \mathrm{~g} / 1$ de solo. O sulfato de amônio foi aplicado com a finalidade de provocar a ocorrência da podridão estilar (RALEIGH \& CHUCKA, 1944; GERALDSON, 1957; WILCOX et alii, 1973).

Os frutos produzidos foram coletados em 11/09/75. Após a colheita determinou-se o número total de frutos; sendo que verificou-se também o número de frutos do tomateiro com podridão estilar. Observou-se a porcentagem de incidência da anomalia fisiológica nos frutos das plantas de tomateiro submetidas aos diferentes tratamentos.

Após a colheita retiraram-se amostragens da haste e folhas de plantas cujos frutos apresentaram-se normais e de plantas cujos frutos mostraram-se com podridão estilar; sendo que frutos normais e frutos apresentando a anomalia fisiológica foram também encaminhados para análise química.

Procedeu-se ainda à retirada de amostras de solo, nos vasos de plantas com frutos normais e nos vasos de plantas cujos frutos mostraram podridão estilar, para serem analisadas quimicamente.

\section{RESULTADOS}

Tabela 1 - Efeito da aplicação de reguladores de crescimento no número total de frutos e no número de frutos apresentando podridão estilar (entre parêntesis), colhidos de tomateiros.

\begin{tabular}{lcrrrrrrrrrr}
\hline \multicolumn{1}{l}{ Tratamento } & \multicolumn{1}{c}{ Repetiçóes } & & Total \\
\hline Controle & $37(10)$ & $40(0)$ & $14(1)$ & $19(0)$ & $7(2)$ & $21(0)$ & $36(1)$ & $7(0)$ & $9(5)$ & $190(19)$ \\
CCC & $30(0)$ & $5(0)$ & $17(0)$ & $15(0)$ & $42(0)$ & $4(1)$ & $2(0)$ & $3(0)$ & $33(3)$ & $151(4)$ \\
SADH & $13(0)$ & $3(0)$ & $9(0)$ & $33(0)$ & $4(0)$ & $3(1)$ & $9(0)$ & $9(0)$ & $13(0)$ & $96(1)$ \\
GA & $18(12)$ & $19(4)$ & $5(0)$ & $3(0)$ & $5(2)$ & $6(0)$ & $4(0)$ & $18(0)$ & $9(0)$ & $87(18)$ \\
IAA & $6(0)$ & $16(3)$ & $3(0)$ & $18(1)$ & $22(0)$ & $17(0)$ & $17(0)$ & $4(0)$ & $16(1)$ & $119(5)$ \\
\hline
\end{tabular}


Verificamos pela observação do número total de frutos e do número de frutos apresentando podridão estilar, colhidos de tomateiros, nos quais provocou-se a ocorrência da anomalia fisiológica com sulfato de amônio, que a porcentagem de frutos com podridão estilar em relação ao número total de frutos mostra-se variável com os diferentes tratamentos. A incidência de podridão estilar mostrou-se da ordem de 10,00\% no controle, 2,65\% nas plantas tratadas com CCC, 1,04\% em SADH, $20,69 \%$ com GA e, finalmente, $4,20 \%$ nos tomateiros tratados com IAA. Isto revela que os tratamentos com SADH, CCC e IAA promovem menor incidência da anomalia fisiológica em relação aos tratamentos com GA e controle. Aplicação da GA aumentou a incidência de podridão estilar.

Tabela 2 - Análise química de amostras de folhas, hastes e frutos de tomateiro, obtidas por ocasião da colheita, em plantas apresentando frutos normais e em plantas mostrando frutos com podridão estilar (entre parêntesis).

\begin{tabular}{lccccc}
\hline Amostra & $\mathrm{N} \%$ & $\mathrm{P} \%$ & $\mathrm{~K} \%$ & $\mathrm{Ca} \%$ & $\mathrm{Mg} \%$ \\
\hline Folhas & $2,64(4,84)$ & $0,34(0,55)$ & $2,82(3,33)$ & $3,18(3,08)$ & $0,62(0,48)$ \\
Hastes & $2,31(2,86)$ & $0,35(0,36)$ & $3,42(3,44)$ & $1,10(0,95)$ & $0,25(0,21)$ \\
Frutos & $2,64(2,97)$ & $0,42(0,49)$ & $3,57(3,71)$ & $0,10(0,06)$ & $0,13(0,12)$ \\
\hline
\end{tabular}

Observamos que os teores de nitrogênio, fósforo e potássio mostraram-se mais altos nas folhas, hastes e frutos de plantas de tomateiro que apresentavam frutos com incidência de podridão estilar, em relação às plantas normais. Verificamos que os níveis de cálcio e magnésio apresentaram-se mais baixos nas folhas, hastes e frutos de tomateiros que mostravam frutos com incidência de podridão estilar, em relação às plantas com frutos normais.

Tabela 3 - Análise química de amostra do solo utilizado no plantio e obtidas por ocasião da colheita, em vasos de plantas apresentando frutos normais e de plantas. mostrando frutos com podridão estilar.

\begin{tabular}{|c|c|c|c|c|c|c|c|}
\hline \multirow{2}{*}{ Amostra } & \multirow{2}{*}{ M.O.\% } & \multirow{2}{*}{$\mathrm{pH}$} & $\mathrm{Al}$ & $\mathrm{Ca}$ & $\mathrm{Mg}$ & $\mathrm{K}$ & $\mathrm{P}$ \\
\hline & & & e. $\mathrm{mg} / 100$ & $\mathrm{ml} \mathrm{de}$ & T. F.S.A. & $\mu \mathrm{g} / \mathrm{ml}$ & T:F.S.A \\
\hline $\begin{array}{l}\text { Plantio } \\
\text { Colheita }\end{array}$ & 1,9 & 6,6 & 0,0 & 2,5 & 0,8 & 155 & $>100$ \\
\hline $\begin{array}{l}\text { (normal) } \\
\text { Colheita }\end{array}$ & 2,2 & 4,6 & 0,3 & 1,7 & 0,2 & 21 & $>100$ \\
\hline (p. estilar) & 1,9 & 4,7 & 0,2 & 1,5 & 0,1 & 17 & 93 \\
\hline
\end{tabular}


A análise química de amostra do solo utilizado no plantio em relação à análise de amostras obtidas por ocasião da colheita, em vasos de plantas apresentando frutos normais e de plantas mostrando frutos com podridão estilar, revelou alguns resultados interessantes. Observou-se um processo de acidificação do solo, no período do plantio à colheita, diminuindo o $\mathrm{pH}$ e aumentando o teor de alumínio.

Notou-se ainda que, a amostra de solo retirada de vasos com plantas apresentando frutos normais, mostrou teores de cálcio, magnésio, potássio e fósforo acima dos níveis da amostra de solo dos vasos de plantas com frutos mostrando podridão estilar.

\section{DISCUSSÃO}

Pelos resultados obtidos (Tabela 1 ), observa-se que a porcentagem de incidência de podridão estilar mostrou-se alta nas plantas tratadas com GA, média no controle e baixa nos tomateiros pulverizados com SADH, CCC e IAA. Considerando-se que, qualquer fator que aumente a transpiração da planta, pode aumentar a probabilidade de incidência da podridão estilar (ROBBINS, 1937), e que o GA estimula as taxas de transpiração (LIVNE \& VAADIA, 1965), pode-se concluir que o GA aumenta a incidência da anomalia fisiológica por elevar a transpiração. BATAL et alii (1972) observaram redução na ocorrência de rachadura dos frutos com aplicação de GA. Diminuição na incidência da podridão estilar foi promovida pelo SADH; sendo que BRYAN \& READ (1972) notaram redução na ocorrência de anomalia fisiológica em tomateiros tratados com SADH. Em macieira, o SADH também reduziu a incidência de anomalia interna nos frutos (LORD et alii, 1967). Redução na incidência da podridão estilar foi verificada com aplicação de CCC; sendo que CASTRO (1973) obteve resultado semelhante e SINGH \& YOUNG (1971) observaram que o CCC promove diminuição na ocorrência de rachadura dos frutos de tomateiro. BRYAN \& READ (1972) verificaram que o CCC aumentou a incidência de parede cinzenta em tomateiro. KNAVEL (1969) observou que tomateiros tratados com CCC possuem teores mais elevados de cálcio, com relação às plantas controle; sendo que KHARANYAN (1967) notou que o CCC reduziu a perda de água das plantas tratadas. Verificou ainda que o retardador de crescimento aumentou a retenção de umidade pela planta; sendo que o crescimento lento das plantas foi associado com baixa ocorrência da podridão estilar no tomateiro (WIERSUM, 1966a). Notou-se baixa ocorrência da anomalia fisiológica em plantas tratadas com IAA. BATAL et alii (1972) verificaram que o IAA reduziu significativamente a incidência de rachadura dos frutos em tomateiro; sendo que HUANG \& HUNG (1957) observaram aumento na ocorrência de lóculos verdes em tomateiros tratados com auxina. 
No que se refere à análise química de amostras de folhas, hastes e frutos de tomateiro, obtidas por ocasião da colheita, em plantas apresentando frutos normais e $\mathrm{em}$ plantas mostrando frutos com podridão estilar, verificou-se que os teores de nitrogênio, fósforo e potássio revelaram-se mais altos em plantas que apresentavam frutos com incidência de podridão estilar (Tábela 2). SHEAR (1975a) considerou que a adubação nitrogenada durante o período inicial de desenvolvimento dos frutos atua na redução de cálcio nos frutos; sendo que o estímulo do nitrogênio para o crescimento, promove uma região de utilização preferencial de cálcio que prejudica sua disponibilidade aos frutos. Realmente, observou-se que amostras que mostravam níveis mais altos de nitrogênio, revelavam níveis inferiores de cálcio. Verificou-se também que amostras que apresentavam teores mais elevados de fósforo, mostraram níveis mais baixos de cálcio (Tabeia 2). ANDERSEN (1971) observou que aplicações de altas concentrações de fósforo promovem điminuição no teor assim como na absorção de cálcio. Notou-se ainda que amostras com niveis mais altos de potássio, possuíam teores mais baixos de cálcio. WILCOX el alii (1973) observaram que aumentando-se - teor de potássio ocorre reduçâo significativa no teor de cálcio. MAYNARD et alii (195'i) consideraram porém, que o teor de potássio nos frutos não foi afetado pela presença da pođridão estilar. RESNIK (1966) observou a existência de fortes interações antagônicas entre o cálcio e o potássio, tanto na absorção como na translocação, exceto um certo estímulo na absorção de potássio, peio cáicio, quando a relação cálcio/potássio do meio é baixa. WIERSUM (1966a) verificou a ocorrência de uma alta correlação entre a incidência de podridão estilar e a relação potássio/cálcio nos frutos. Os resuitados obtidos no presente trabalho mostram-se de acordo com aqueles obtidos por WILCOX et alii (1973), os quais observaram que aplicação de nitrogènio amoniacal em tomateiro promoveu redução de cálcio nos tecidos até níveis de deficiência ou próximos desses. HOFF et alii (1974) sugeriram que a toxicidade do amônio é uma manifestação da deficiência intracelular de cálcio. MAYNARD et alii (1957) observaram que o teor de cálcio nos frutos normais mostrava-se superior ao encontrado em frutos afetados pela podridão estilar, resultado semelhante ao obtido no presente ensaio. RALEIGH \& CHUCKA (1944) verificaram que, quando a concentração de cálcio nos frutos mostra-se inferior a $0,2 \%$, observa-se a incidência da podridão estilar em alguns frutos. MAYNARD et alii (1957) consideraram que a concentração de cálcio em frutos com podridão estilar é da ordem de $0,04 \%$ e nos frutos sadios 0,06\%. DECHEN et alii (1973) observaram que frutos livres de podridão estilar apresentam a concentração percentual de cálcio entre 0,16 e 0,21 para a linhagem Samano e de 0,15 e 0,24 para a linhagem Kada. Os resultados obtidos no presente ensaio, com a cultivar "Miguel Pereira", mostram-se com valores abaixo dos obtidos por DECHEN et alii (1973) e acima daqueles apresentados por MAYNARD et alii (1957), pois, frutos com podridão estilar continham $0,06 \%$ de cálcio e frutos sadios apresentavam $0,1 \%$ do elemento (Tabela 2). DECHEN et alii (1973) observaram que 
as linhagens Samano e Kada acham-se bem supridas em cálcio quando a primeira folha apresentar concentração percentual de cálcio entre 3,11 e 3,25, aos 90 dias de idade da planta. Verificamos que folhas de plantas sadias de "Miguel Pereira" mostraram 3,18\% de cálcio por ocasião da colheita, sendo que folhas de plantas que apresentavam frutos com podridão estilar continham 3,08\% de cálcio, mostrando-se de acordo com os limites estabelecidos por DECHEN et alii (1973). Aplicação de nitrogênio em tomateiro, promoveu redução no teor de magnésio nos tecidos até níveis de deficiência ou próximos desses; sendo que aumentando-se o teor de potássio teve-se também uma redução significativa no teor de magnésio (WILCOX et alii, 1973). Estes resultados mostram-se semelhantes aos obtidos no presente ensaio.

Os resultados das análises químicas de amostra do solo utilizado no plantio, com relação às análises de amostras obtidas por ocasião da colheita, em vasos com plantas sadias e em vasos com plantas mostrando frutos com podridão estilar, apresentaram valores muito altos de fósforo e potássio. Os níveis de fósforo mantiveram-se elevados, sendo que os teores de potássio reduziram mais pronunciadamente no solo com plantas que mostraram podridão estilar. Amostra do solo retirada de vasos com plantas sadias, mostrou-se com níveis de cálcio e magnésio acima dos níveis da amostra do solo de vasos com plantas de frutos apresentando a anomalia fisiológica (Tabela 3). Estes resultados, de acordo com os conceitos de BROOKS (1914), RALEIGH \& CHUCKA (1944), GERALDSON (1957), RESNIK (1966) e ANDERSEN (1971) indicam que altos níveis de nitrogênio, fósforo, potássio e magnésio no solo podem promover a incidência da podridão estilar, causada pela deficiência de cálcio no fruto.

SHEAR (1975b) apresentou extensa revisão relacionando anomalias fisiológicas em vegetais com déficit de cálcio: ROBBINS (1937) observou que aumento na concentração da solução do solo pode induzir a ocorrência de podridão estilar em frutos de tomateiro; sendo que Mc ALPINE (1913) considerou que a podridão estilar é promovida pela redução no teor de água no tecido, como resultado da transpiração excessiva e rápido crescimento. WEDGEWORTH et alii (1927) reduziram a ocorrência de podridão estilar com sombreamento; sendo que STOSSER (1970) verificou que 98 a $99 \%$ do cálcio - 45 injetado em tomateiro moveu-se para as folhas, e somente 1 a $2 \%$ dirigiu-se aos frutos. FAUST \& SHEAR (1968) observaram que a prática do anelamento aumentou a ocorrência de anomalia, sendo que o desfolhamento reduziu. Isto pode sugerir que o anelamento reduziu a translocação de cálcio, sendo que o desfolhamento reduziu a transpiração, promovendo movimentação de cálcio aos frutos; pois, GERARD \& HIPP (1968) notaram que alta transpiração reduz, e baixa transpiração aumenta o movimento de cálcio para o fruto de tomateiro. GOODE \& INGRAM (1971) mostraram que redução na umidade do solo aumenta a concentração de cálcio nas folhas e reduz nos frutos. Pode-se considerar que baixa umidade no 
solo impede a absorção ativa que promove uma tendência de movimento de cálcio aos frutos. PALZKILL \& TIBBITTS (1975) observaram que o acúmulo de cálcio-45 nas folhas internas de couve aumentou mais de oito vezes quando as folhas externas estavam sob condições de baixa transpiração e alta absorção ativa, comparativamente com condições que maximizam a transpiração e reduzem a absorção ativa.

O sulfato de amônio promove a ocorrência de podridão estilar por causar acidificação do solo, rápida lavagem do cálcio remanescente e redução na absorção de cálcio por competição. Condições de seca, após um período chuvoso, parecem propícias à incidência da anomalia em tomateiros. Pode-se considerar que durante o período nublado e chuvoso a absorção ativa poderá suprir os frutos com teores adequados de cálcio, em ausência de transpiração foliar. Em condições de seca teremos predomínio da absorção passiva, sendo que a alta transpiração foliar promove aumento no teor de cálcio nas folhas e redução nos frutos; deve-se considerar também o aumento na concentração da solução do solo em condições de seca. FAUST \& SHEAR (1972) observaram que a transpiraçäo de maçãs pode ser inversamente relacionada com o conteúdo de cálcio na polpa. Altos níveis de nitrogênio aumentam a respiração, sendo que altos teores de cálcio reduzem o efeito do nitrogênio na respiração. O nitrogênio amonical eleva mais pronunciadamente a respiração do que a forma nítrica. Com baixo teor de cálcio o fruto perde 30 a $70 \%$ de sua capacidade de sintetizar proteínas e ácidos nucleicos, ocorre decréscimo na síntese de clorofila, aumento no espaço livre aparente e na permeabilidade hidráulica.

O CCC aumenta o número de células no parênquima paliçádico e diminui os espaços intercelulares; deste modo, a rápida perda de água tende a decrescer, sendo que aumenta a eficiência do movimento hídrico através dos tecidos foliares. Como efeito do movimento hídrico mais efetivo pode ocorrer menor absorção de água do solo. O CCC pode aumentar a tolerância das plantas ao déficit hídrico por sua interferência na biossíntese de GA. Baixo teor de GA endógeno pode promover redução na abertura estomática e diminuição na transpiração, resultando em um equilíbrio hídrico mais favorável (LIVNE \& VAADIA, 1972). O SADH aumenta a turgidez relativa, mas pode reduzir a taxa de absorção de água (LEE et alii, 1974); SADH e IAA promovem aumentos na translocação de cálcio-45 em hastes de feijoeiro (WIENEKE et alii, 1971). Observou-se que o GA tende a diminuir a absorção de nutrientes (CHEN, 1964); sendo que reduz a absorção de cálcio-45 (WIENEKE et alii, 1971).

Pode-se considerar que a maior incidência de podridão estilar nos frutos de tomateiros tratados com GA deve-se ao maior crescimento e ao menor potencial osmótico em plantas tratadas com o regulador de crescimento (CASTRO, 1976), ao cálcio e água no xilema (REDMOND, 1975) e floema (WIERSUM, 1966b), à maior transpiração foliar (LIVNE \& VAADIA, 1965) e à ocorrência de menor teor de cálcio nos frutos 
(Tabela 2). Plantas tratadas com CCC mostraram baixa incidência de podridão estilar devido à maior absorção de cálcio, ao menor crescimento, à manutenção de elevado potencial osmótico foliar (CASTRO, 1976), ao cálcio e água no sistema vascular (REDMOND, 1975; WIERSUM, 1966b), à menor transpiração foliar (CASTRO \& BALLESTERO, 1977) e à ocorrência de maior teor de cálcio nos frutos (Tabela 2). Tratamento com SADH reduziu a ocorrência da podridão estilar porque, apesar de reduzir o potencial osmótico foliar, retardou o crescimento e diminuiu a razão de área foliar (CASTRO, 1976); sendo que reduziu a transpiração foliar (CASTRO \& BALLESTERO, 1977) e aumentou o teor de cálcio nos frutos (Tabela 2). Aplicação de IAA diminuiu a incidência de podridão estilar porque, apesar de promover maior crescimento foliar e aumentar o peso da matéria seca, manteve elevado o potencial osmótico foliar (CASTRO, 1976), reduziu a transpiração (JOHANSEN, 1954) e aumentou o teor de cálcio nos frutos (Tabela 2). O esquema seguinte apresenta, de acordo com a discussão, o efeito de reguladores de crescimento na incidência da podridão estilar:

\section{CONCLUSÕES} clusões:

Os resultados obtidos neste ensaio, permitem as seguintes con-

1. Tratamento com ácido giberélico promove alta incidência de podridão estilar, sendo que as plantas afetadas apresentam menor teor de. cálcio nos frutos.

2. Aplicação de cloreto de (2-cloroetil) trimetilamônio causa baixa incidência de podridão estilar, sendo que as plantas tratadas mostram maior teor de cálcio nos frutos.

3. Frutos de tomateiro cultivar "Miguel Pereira" com $0,10 \%$ de cálcio apresentam-se normais, sendo que frutos com $0,06 \%$ do elemento mostram-se com podridão estilar.

4. Folhas da cultivar "Miguel Pereira" com 3,18\% de cálcio pertencem a plantas normais, sendo que plantas com podridão estilar apresentam $3,08 \%$ de cálcio nas folhas.

5. A manutenção de níveis mais elevados de cálcio no solo previne a ocorrência da podridão estilar.

6. Aplicação de sulfato de amônio em altas concentrações promove acidificação do solo, lavagem do cálcio e possibilidade da ocorrência de podridão estilar. 


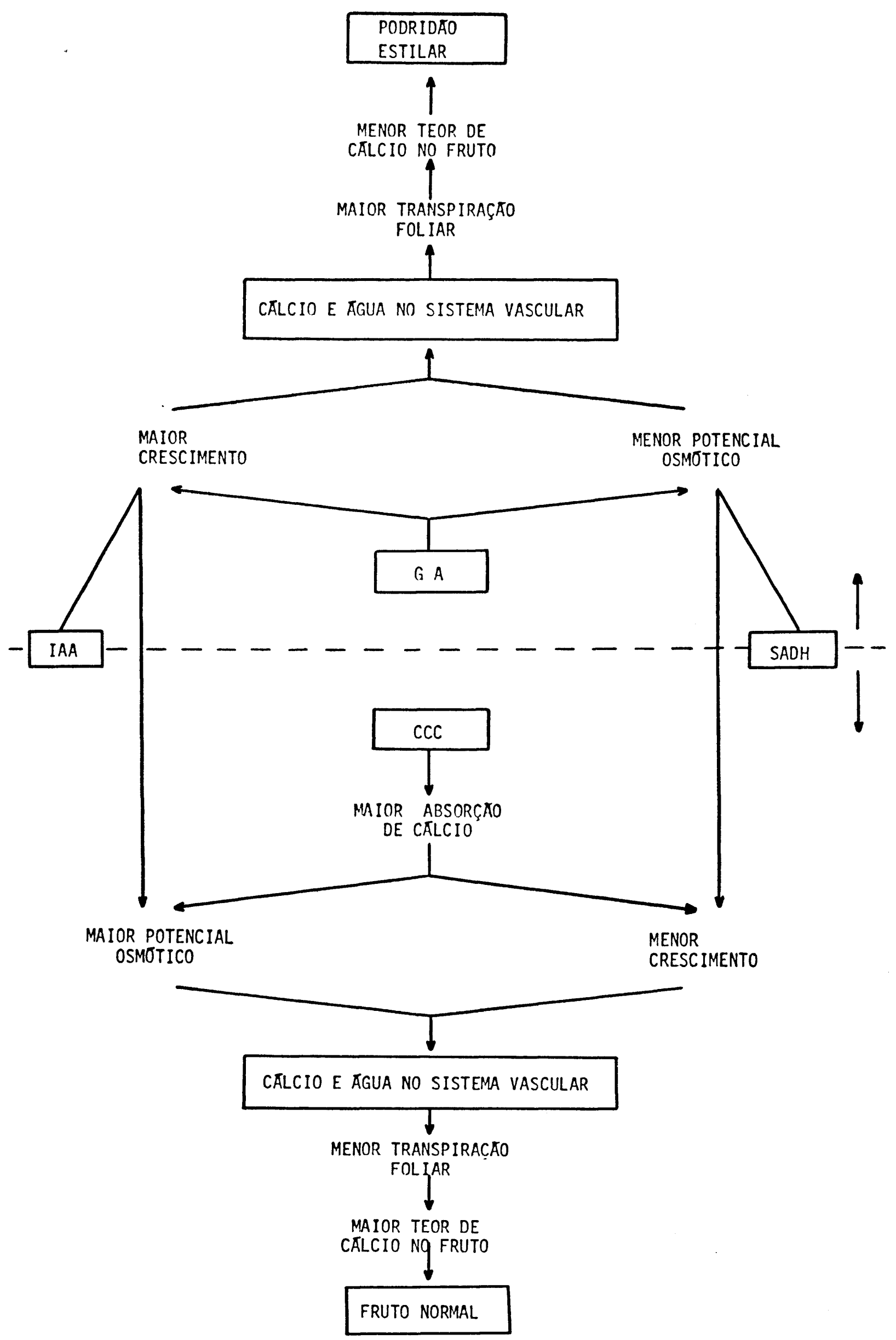


SUMMARY OCCURRENCE OF BLOSSOM-END ROT IN TOMATOES (LYCOPERSICON
ESCULENTUM MILL.) UNDER EFFECT OF GROWTH REGULATORS

It was observed that gibberellic acid $100 \mathrm{ppm}$ promotes high incidence of blossom-end rot when a high level of ammonium sulphate was used. Under the same conditions, treatments with succinic acid -2,2-dimethylhydrazide 4,000 ppm, (2-chloroethyl) trimethylammonium chloride 2,000 ppm and indole-3-acetic acid $100 \mathrm{ppm}$, caused low incidence of blossom-end rot. It was proposed a mechanism of blossom-end rot incidence in tomatoes.

\section{LITERATURA CITADA}

ANDERSEN, A.J. 1971. Influence of phosphorus and nitrogen nutrition on uptake and distribution of strontium and calcium in oat plants. Soil Sci. Soc. Amer. Proc. $35(1): 108-111$.

BATAL, K.M.; WEIGLE, J.L.; LERSTEN, N.R. 1972. Exogenous growth regulator effect on tomato fruit cracking and pericarp morphology. J. Amer. Soc. Hort. Sci. $97(4): 52.9-531$.

BROOKS C. 1914. Blossom-end rot of tomatoes. Phytopath. 4:345-373.

BRYAN, H.H. ; READ, P.E. 1972. Effects of seedling applications of alar, cycocel and ethrel on graywall and tomato yield concentration. HortScience 7(3):326.

CASTRO, P.R.C. 1973. Efeito do CCC na podridão estilar de tomateiro do grupo Santa Cruz. Supl. Ciência e Cultura 25(6):319.

CASTRO, P.R.C. 1976 Efeitos de reguladores de crescimento em tomateiro (Lycopersicon esculentum Mill.) Tese de Doutorado. Universidade de São Paulo. 148 p.

CASTRO, P.R.C.; BALLESTERO, S.D. 1977. Efeitos de reguladores de crescimento na transpiração do tomateiro (Lycopersicon esculentum Mill. cv. 'Miguel Pereira'). Rev. de Agric. 52 (2-3):147-152.

CHEN, C.C. 1964. The absorption and mobility of root and foliar applied calcium, sulfur, zinc and iron by tomato seedlings as influenced by gibberellin treatments. Bot. Bull. Acad. Sinica $5: 17-25$.

DECHEN, A.R.; OLIVEIRA, G.D.; HAAG, H.P. 1973. Nutrição mineral de hortaliças. XXIII. Influência do cálcio no desenvolvimento do tomateiro, variedade Santa Cruz, linhagem Kada e Samano. An. Esc. Sup. Agr. "Luiz de Queiroz" 30:305-315.

FAUST, M.; SHEAR, C.B. 1972. The effect of calcium on respiration of apples. J. Amer. Soc. Hort. Sci. $97(4): 437-439$.

GERALDSON, C.M. 1957. Factors affecting calcium nutrition of celery, tomato and peppers. Proc. Soil. Sci. Soc. Amer. $21: 621-625$.

GERARD, C.J.; HIPP, B.W. 1968. Blossom-end rot of 'Chico' and 'Chico Grande' tomatoes. Proc. Amer. Soc. Hort. Sci. $93: 521-531$.

GOODE, J.E.; INGRAM, J. 1971. The effect of irrigation on the growth, cropping and nutrition of Cox's orange pippin apple trees. J. Hort. Sci. 46:195-208. 
HOFF, J.E.; WILCOX, G.E.; JONES, C.M. 1974 - The effect of nitrate and ammonium nitrogen on the free amino acid composition of tomato plants and tomato fruit. J. Amer. Soc. Hort. Sci. $99(1): 27-30$.

HUANG, H.; HUNG, L. 1957 - The fruit quality of tomatoes as affected by para-clorophenoxyacetic acid (PCA) for increasing fruit set during cool seasons. Mem. Coll. Agric. Taiwan Univ. 4(4):27-45.

JOHANSEN, S. 1954 - Effect of indole-acetic acid on stomata and photosynthesis. Physiol. Plant. $7: 531$.

KHARANYAN, N.N. 1967 - Effect of 2-chloroethyltrimethylammonium chloride (CCC) on some characteristics of the water conditions in plants. Fiziologiya Rastenii 14(3): 548-551.

KNAVEL, D.E. 1969 - Influence of growth retardants on growth, nutrient content and yield of tomato plants grown at various fertility levels. J. Amer. Soc. Hort. Sci. $94: 32-35$.

LEE, K.C. ; CAMPBELL, R.W.; PAULSEN, G.M. 1974 - Effects of drought stress and succinic acid -2,2- dimethylhydrazide treatment on water rclations and photosynthesis in pea seedlings. Crop Science $14: 279-282$.

LIVNE, A.; VAADIA, Y. 1965 - Stimulation of transpiration rate in barley leaves by kinetin and gibberellic acid. Physiol. Plant. 18:658-644.

LORD, W.J.; SOUTHWICK, F.W.; DAMON, R.A. 1967 - The influcnce of N-dimethyl amino succinamic acid an flesh firmness and on some pre and post-harvest physiological disorders of "Delicious" apples. Proc. Amer. Soc. Hort. Sci. 91:829-832.

MALAVOLTA, E.; CASTRO, P.R.C.; CRUZ, V.F.; YAMADA, T. 1975 - Calcium and its relationship to blossom-end rot in tomato. Comm. Soil Sci. Plant Anal. 6(3): 273-284.

MAYNARD, D.N. ; BARHAM, W.S.; MC COMBS, C.L. 1957 - The effect of calcium nutrition of tomatoes as related to the incidence and severity of blossom-rot. Proc. Amer. Soc. Hort. Sci. $69: 318-322$.

MC ALPINE, D. 1913 - The cause of bitter pit, its contributing factors. Melbourne, Progr. Rpt. Commonw. Australia 2:94-95.

PALZKILL, D.A.; TIBBITTS, T.W. 1975 - Control of calcium movement in cabbage by relative humidity and suggested relation to calcium-related disorders in plants. HortScience 10(3):388.

RALEIGH, S.M.; CHUCKA, J.A. 1944 - Effect of nutrient ratio and concentration on growth and composition of tomato plants and the occurrence of blossom-end rot the fruit. Plant Physiol. $19: 671-678$.

REDMOND, W.J. 1975 - Transport of calcium in apple trees and its penetration into the fruit. Comm. Soil Sci. Plant Anal. 6(3):261-272.

RESNIK, M.E. 1966 - Absorción, translocación e interacciones del potasio y el calcio en plantas de cebarda y poroto. Rev. Inv. Agr. 3(19):291-325.

ROBBINS, W.R. 1937 - Relation of nutrient salt concentration to growth of the tomato and to the incidence of blossom-end rot of the fruit. Plant Physiol. $12: 21-50$.

SHEAR, C.B. 1975a - Calcium nutrition and quality in fruit crops. Comm. Soil Sci. Plant Anal. 6(3) :233-244.

SHEAR, C.B. 1975b - Calcium-related disorders of fruits and vegetables. HortScience $10(4): 361-365$. 
SINGH, K.; YOUNG, J.O. 1971b - Effect of 2-chloroethyl trimethyl ammonium chloride on growth behavior and transpiration related to tomato fruit cracking. T. Nkvv. Res. J. $5(1): 22-27$.

STÖSSER, R. 1970 - Translokation and Verteilung von ${ }^{45}$ Calcium und Phosphor bei Früchten von Prunus avium L. in Beziehung zum Fruchtfall. Angew. Botanik 44: 153-165.

WEDGEWORTH, H.H.; NEAL, D.C.; WALLACE, J.M. $1927 \rightarrow$ Wilt and blossom-end rot of tomato. Mississippi Agr. Expt. Sta. Bull. 247.

WIENEKE, J.; BIDDULPH, O.; WOODBRIDGE, C.G. 1971 - Influence of growth regulating substances on absorption and translocation of calcium in pea and bean. J. Amer. Soc. Hort. Sci. 96(6):721-724.

WIERSUM, L.K. 1966a. - The calcium supply of fruits and storage tissues in relation to water transport. Acta Hort. Int. Soc. Hort. Sci. $4: 33-38$.

WIERSUM, L.K. $1966 \mathrm{~b}$ - Calcium content of fruits and storage tissues in relation to the mode of water supply. Acta Bot. Neerl. $15: 406-418$.

WILCOX, G.E.; HOFF, J.E.; JONES, C.M. 1973 - Ammonium reduction of calcium and magnesium content of tomato and sweet corn leaf tissue and influence on incidence of blossom-end rot of tomato fruit. J. Amer. Soc. Hort. Sci. 98(1):86-89. 
